\title{
AN ELECTROPHYSIOLOGICAL STUDY OF TRANSMISSION FROM INTRAMURAL EXCITATORY NERVES TO THE SMOOTH MUSCLE CELLS OF THE CHICKEN OESOPHAGUS
}

\author{
Hidenori OHASHI \\ Department of Pharmacology. Faculty of Veterinary Medicine, Hokkaido University, Sapporo \\ Received for publication March 20, 1971
}

A fairly large number of papers dealing with the excitatory junction potential evoked by cholinergic nerve stimulation are now available (1-5). However, information about transmission from cholinergic nerves to smooth muscle cells is much less than about transmission from adrenergic nerves. This seems to be because there is no suitable preparation like the hypogastric nerve-vas deferens of the guinea-pig. Most smooth muscle cells previously used have both excitatory and inhibitory innervation and the excitatory response croked by transmural stimulation may be modified by the inbibitory one.

The aim of the present work is to investigate transmission from cholinergic nerves to smooth muscle cells using isolated strips of smooth muscle from the longitudinal layer of the upper oesophagus as far as the crop of the chicken. It has been reported that this part of the oesophagus of the chicken receives only cholinergic excitatory innervation (6, 7). As a first step toward studying the transmission, observations were made on the membrane activity of the muscle and these also are presented in this paper.

The results show that the cholinergic nerve-smooth muscle junction operates by the substantially same manner as that for the sympathetic nerve-smooth muscle junction of the guinea-pig vas deferens or other neuro-effector junctions.

Prcliminary accounts of some of the results have already been published (8).

\section{MATERIALS AND METHODS}

Adult or young chickens within 5 weeks after hatching were killed by bleeding. The upper oesophagus as far as the crop was exposed and then isolated. Strips, about $20 \mathrm{~mm}$ in length and $1 \mathrm{~mm}$ in width, were cul of by fine scissors from the longitudinal layer of the oesophagus under a binocular microscope. They were mounted in a sucrose-gap apparatus as described by Stämpfli (9) and Burnstock and Straub (10). A pair of platinum electrodes for transmural stimulation were embedded in the vertical tube of the apparatus through which flowed Krebs solutions, so that stimuli could be given across part of the strip $3 \mathrm{~mm}$ apart from the recording electrode. The transmural stimulation was effected by a stimulator with single square pulses lasting 0.3 milliseconds or less. The membrane potential change was measured extracellularly by a pair of $\mathrm{Ag}-\mathrm{AgCl}$ electrodes. The electrodes were connected to a pair of cathode followers and the potential was amplified by a DC amplifier and recorded on a pen-oscillograph simultaneously with a tension 
change. The change in tension was mediated by a mechanoelectronic transducer (RCA 5734). In some experiments both electrical and mechanical activities were displayed on beams of an oscilloscope and recorded on a film.

The Krebs solution used contained $(\mathrm{mM}): \mathrm{Na}^{+} 137.4, \mathrm{~K}^{+} 5.9, \mathrm{Mg}^{++} 1.2, \mathrm{Ca}^{++}$2.5, $\mathrm{Cl}^{-} 134, \mathrm{H}_{2} \mathrm{PO}_{4}^{-} 1.2, \mathrm{HCO}_{3}-15.5$, glucose 11.5 , and was aerated with $95 \% \mathrm{O}_{2}+5 \% \mathrm{CO}_{2}$.

The following drugs werc used: acetylcholine chloride (Roche and Daiichi), atropine sulfate (Tanabe and Merk), adrenaline hydrochloride (Sankyo), noradrenaline hydrochloride (Sankyo), hexamethonium bromide (Yamanouchi) and tetrodotoxin (Sankyo).

All concentrations of drugs in the present paper, unless otherwise stated, were expressed in terms of their respective salts in gram per milliliter.

\section{RESULTS}

A. Membrane potential and spontaneous activities

1) Membrane potential

The resting membrane potential of preparations was measured by substituting an isotonic $\mathrm{K}_{2} \mathrm{SO}_{4}$ solution for Krebs solution. The range of the observed values was from 39 to $53 \mathrm{mV}$ (mean + S.E.: $47 \pm 2.5 \mathrm{mV}, \mathrm{n}=14$ ). The variation of the membrane potential might be due mainly to the degree of the stretch $(11,12)$, but this was not carefully observed.

\section{2) Spontaneous electrical and mechanical activities}

Some, but not all, preparations showed spontaneous electrical and mechanical activities 30 minutes or more after mounting in a sucrose-gap apparatus under moderate tension. Fig. 1 shows the typical electrical and mechanical activities. The action potentials discharged with considerable variation in both amplitude and shape. Individual action potentials ranged in amplitude from less than $5 \mathrm{mV}$ up to $25 \mathrm{mV}$ and the most frequently observed shape of discharge consisted of complex spikes, two or more spikes occurring before the repolarization of the preceding spike was complete. Simple spikes were sometimes discharged and their amplitude was usually larger than the complex spikes. This is to be expected, since the external electrodes are in contact with a number of smooth muscle cells, some of which may be firing asynchronously. It was found that application of acetylcholine and stimulation of the intramural nerves made the action potentials larger and

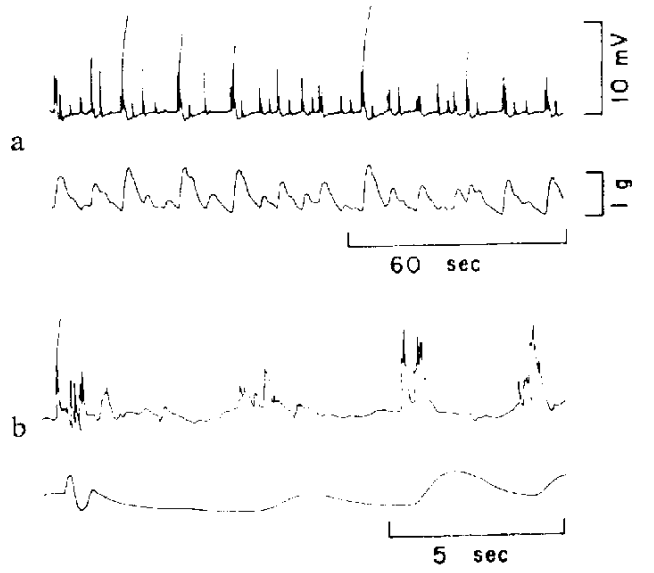

Fig. 1. Spontaneous electrical and mechanical activities. Upper trace is the membrane potential; lower trace, isometric tension. (a), (b) Records from two different strips at two different speeds. Note considerable variation of spikes in their amplitude, shape and discharge interval. For further description see text. 
a

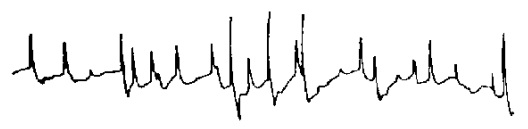

rmmonthomen

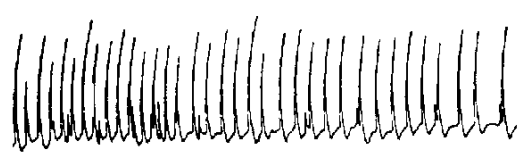

b

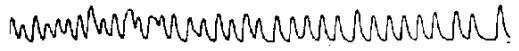

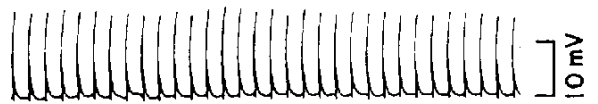

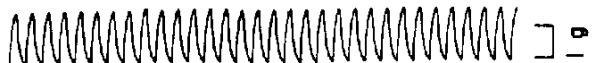

$60 \mathrm{sec}$

FIG. 2. Comparison of spontaneous activities before and after application of acetylcholine, with responses to transmural stimulation.

(a) Spontaneous activities just before and (b) 1 minutc after application of acetylcholine, $5 \times 10^{-\mathrm{s}}$; (c) electrical and mechanical responses produced by transmural stimulation with squarc pulses of $0.1 \mathrm{msec}$ duration and $25 \mathrm{~V}$ at a frequency of $0.2 \mathrm{~Hz}$. For further description see text.
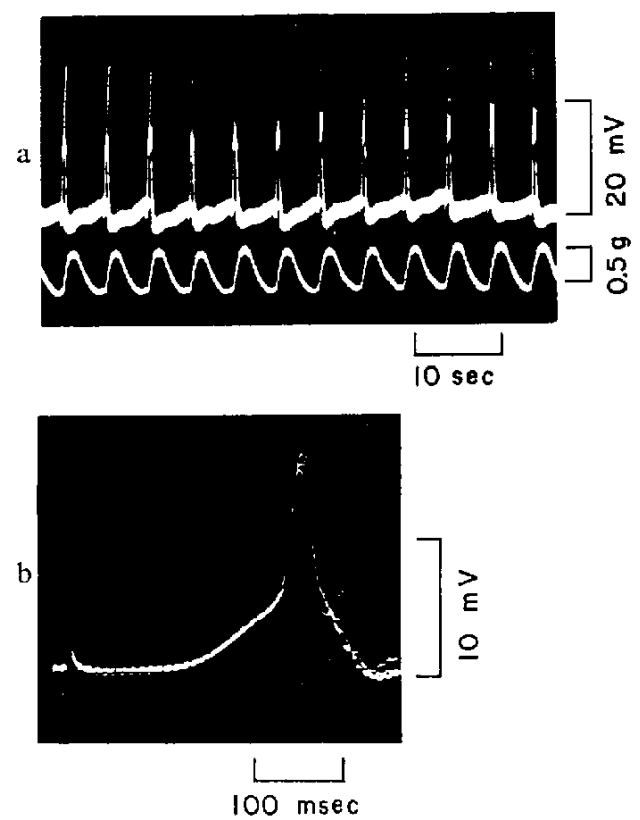

Fic. 3. Action potentials and contractions in response to transmural stimulation.

(a) Responses produced by transmura1 stimulation with square pulses of 0.1 msec duration and $25 \mathrm{~V}$ at a frequency of $0.2 \mathrm{~Hz}$; (b) superimposed record of five action potentials at faster speed. Note the long latency and transition from the slow phase of depolarization to the spike.

more consistent in their amplitude and more regular in their shape (Fig. 2). The intervals between spontaneous discharges also varied, from a few seconds to 60 seconds or so. In some preparations, in the course of prolonged recording, spontaneous spike activity ceased periodically and the pauses between bursts of activity became progressively longer.

Normally each discharge of spikes was associated with a contraction of the preparation, but this was not so in some preparations. This dissociation between electrical and mechanical events was observed more frequently in preparations from young chickens.

\section{B. Transmission from intramural nerves}

\section{I) Responses to transmural stimulation}

Preparations with little spontaneous activity permitted observation of responses to transmural stimulation. Stimulation with single square pulses gave a depolarizing response, but no hyperpolarizing response. The depolarization initiated an action potential, thus resulting in a contraction. The evoked action potentials were larger in amplitude than spontaneously discharged action potentials. Fig. $3 a$ shows action potentials and 

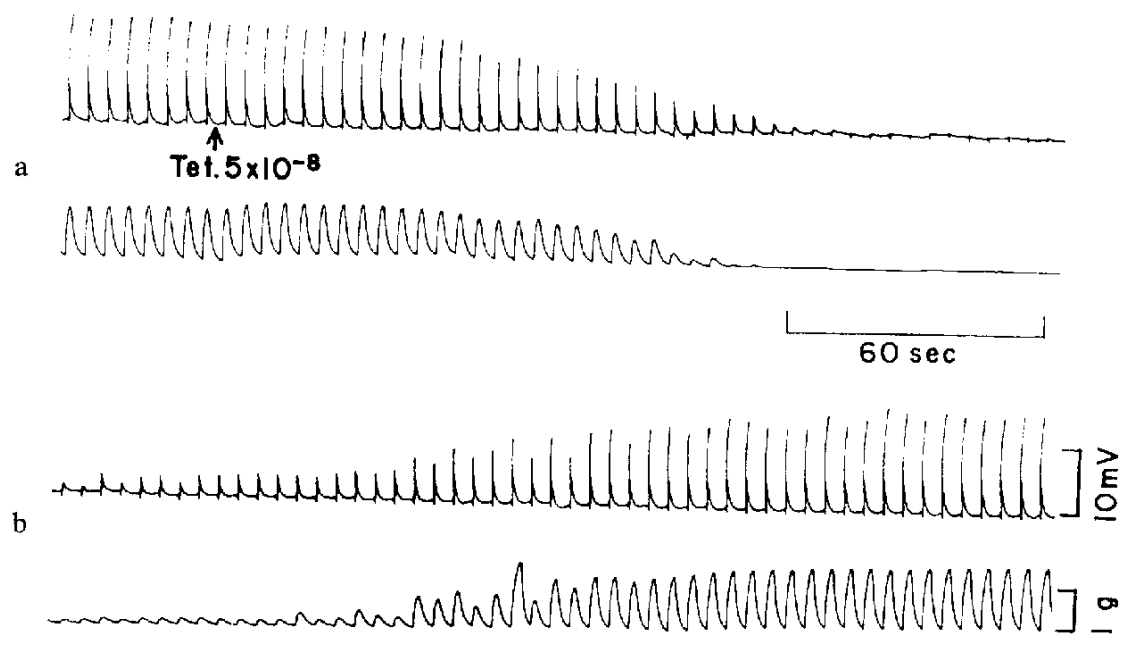

FIG. 4. Effect of tetrodotoxin on responses to transmural stimulation.

(a), (b) Continuous records. Tetrodotoxin, $5 \times 10^{-8}$, was applied at arrow Tet. in (a) and it was washed out between (a) and (b). Stimuli with square pulses of $0.25 \mathrm{~m}$ sec duration and $10 \mathrm{~V}$ at a frequency of $0.2 \mathrm{~Hz}$ were used.

contractions recorded during repetitive stimulation. The spike potentials generally arose from a phase of slow depolarization. Fig. 3b illustrates the transition from the slow phase of depolarization to the spike and also the long latency from stimulus artifact to initiation of the response. When the interval of repetitive stimulation was shorter than 5 seconds, the amplitude of the response decreased. The following characteristics of the responses indicate that Iransmural stimulation causes excitation of the intramural nerves, rseulting in release of a transmitter from their endings which has an excitatory effect on smooth muscle, thus leading to excitation of the oesophageal muscle cells: l) The strength-duration curve for the response with its maximum size was a simple hyperbola and the chronaxie was estimated to be 0.1 millisecond. This is incompatible with the chronaxie of the spike of intestinal smooth muscle which is of the order of 10 milliseconds $(13,14)$. 2) The latency, of more than 100 milliseconds, appears to be much longer than the time taken in conducting a spike from the site at which it discharged to the recording electrode (about $3 \mathrm{~mm}$ ), since the range of the conduction velocity of smooth muscle is from $2 \mathrm{~cm}$ per second to $10 \mathrm{~cm}$ per second $(13-18)$. 3) The response was completely abolished with tetrodotoxin at concentrations of $10^{-k}$ or more (Fig. 4). It is well known that tetrodotoxin bocks the action potential in nerve $(19,20)$, but it has no effect on the action potential in smooth muscle $(21,22)$.

Thus the slow phase of depolarization, which is usually observed preceding the spike, is interpreted as an excitatory junction potential (EJP).

\section{2) Characteristics of the EJP}

The EJPs in response to transmural stimulation, described above, were always followed by the generation of spikes. In the presence of spikes, however, one has no direct indication of the time course and characteristics of the EJP, because spikes usually wiped 
out the EJP and, if not, they complicated it. To overcome such difficulties the following attempts were made to obtain an EJP without a spike. First, the changes in membrane potential were recorded during submaximal stimulation. The stimulus intensity was gradually decreased with a constant duration (0.1 millisecond). However, it was found that the amplitude of EJPs as well as that of spikes were diminished as the stimulus intensity was decreased. Secondly, atropine was used at low concentrations $\left(1 / 2 \times 10^{-8}\right.$ and $\left.10^{-8}\right)$. In the presence of atropine intramural nerve stimulation gave EJPs which failed to reach the excitation threshold and consequently no spike was croked. The EJPs, however, did not persist, that is, their amplitude was gradually diminished until eventually they became undetectable. If an appropriate concentration was used, it might be possible to obtain EJPs without diminishing their amplitude. Finally, the magnesium content of Krebs solution was increased up to 20 millimolar. It has been shown that an excess of magnesium ions blocks neuromuscular transmission at skcletal muscle and the effect is due manily to a reduction in the amount of released
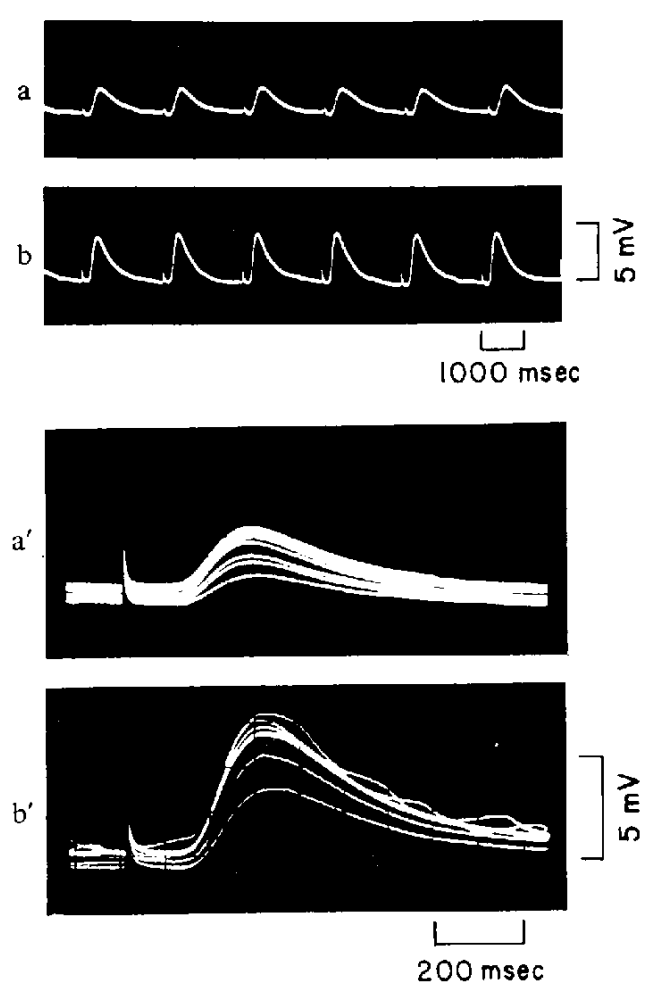

FIG. 5. EJPs in response to stimulation of intramural nerves at different stimulusintensities with a constant pulse duration.

(a), ( $\left.\mathbf{a}^{\prime}\right)$ EJPs at $20 \mathrm{~V}$ stimulus-intensity: (b), (b') EJPs at $30 \mathrm{~V}$ stimulusintensity. (a), (b) Records from a strip in Krebs solution containing $10 \mathrm{~mm}$ magnesium ions; $\left(a^{\prime}\right),\left(b^{\prime}\right)$ superimposed records from another strip in Krebs solution containing $20 \mathrm{~mm}$ magnesium ions. Stimulus-duration of $0.1 \mathrm{msec}$ was used at frequencies of $0.8 \mathrm{~Hz}$ in (a) and (b), and of $0.6 \mathrm{~Hz}$ in $\left(a^{\prime}\right)$ and $\left(b^{\prime}\right)$, respectively.

transmitter (23). In the magnesium-treated preparations it was observed that action potentials failed to fire, leaving merely EJPs. Their amplitude diminished further to some extent and then became constant and remained so as long as the preparation was exposed to the high-magnesium solution. Therefore, the experiments studying the characteristics of EJPs were carried out in a high-magnesium solution.

a) Facilitation and summation: The EJPs showed an increase in amplitude as the strength of stimulation was increased as illustrated in Fig. 5. This could be due to a multiple innervation of individual cells as is the case in the smooth muscle cells of the guineapig vas deferens (24), or alternatively, 10 an increase of number of motor units involved. The present experiments have not, however, differentiated between these two possibilities. 

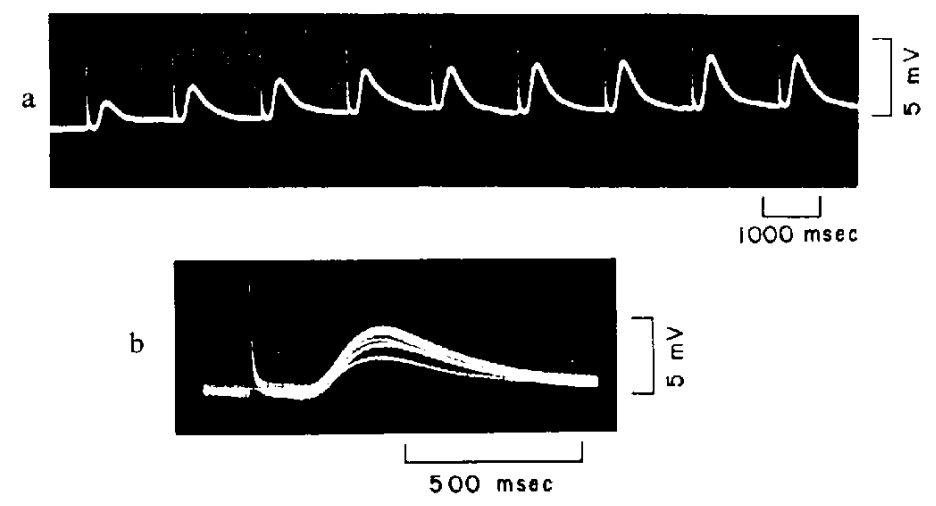

FIG. 6. Facilitation of FJPs in response to repetitive stimulation of intramural nerves.

(a) Record of EJPs from a strip in Krebs solution containing $10 \mathrm{~mm}$ magnesium ions, stimuli of $0.3 \mathrm{msec}$ duration and $20 \mathrm{~V}$ being used at a frequency of $0.8 \mathrm{~Hz}$; (b) Superimposed record of five EJPs from another strip in Krebs solution containing $20 \mathrm{~mm}$ magnesium ions, stimuli of $0.1 \mathrm{msec}$ duration and $20 \mathrm{~V}$ being used at a frequency of $0.6 \mathrm{~Hz}$.

The EJPs also increased in anplitude with successive stimuli, and reached their maximum after several stimuli (facilitation) (Fig. 6). The facilitation occurred even when the interval between stimuli exceeded one second. At frequency from 0.5 to $0.9 \mathrm{~Hz}$, facilitation occurred in the absence of any significant change in the resting membrane potential. At higher frequency $(1$ or $2 \mathrm{~Hz})$ summation occurred so that successive EJPs arose from a reduced membrane potential. Sometimes the EJP triggered a spike even in a solution containing high magnesium ions.

b) Time course: The time course of the EJP was different from preparation to preparation, although it was consistent if the record was taken from the same preparations. The following ranges (and mean with $\mathrm{S}$.E. values) were obtained from 21 preparations. The delay between nerve stimulation and the onset of the EJP was from 90 to 160 milliseconds (mean, $120 \div 15$ milliseconds); the time to reach its maximum height was from 200 to 410 milliseconds (mean, 280 15 milliseconds); the time to decay to the half-amplitude was from 130 to 300 milliseconds (mean, $200 \pm 10$
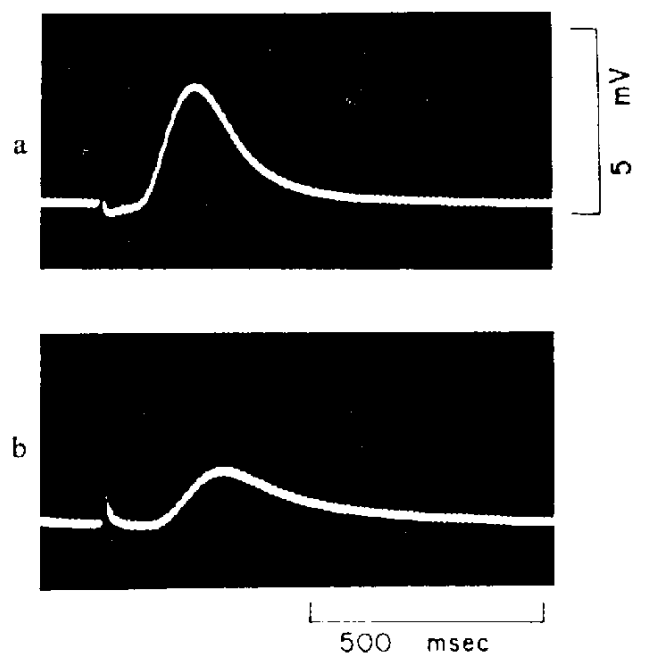

Fig. 7. EJPs in response to stimulation of intramural nerves, recorded at different distances from the stimulating electrodes.

(a) Record at $3 \mathrm{~mm}$ distance; (b) record at $5 \mathrm{~mm}$ distance. Krebs solution containing $20 \mathrm{~mm}$ magnesium ions and stimuli with square pulses of $0.1 \mathrm{msec}$ duration and $30 \mathrm{~V}$ were used in both (a) and (b). 
milliseconds) and it lasted from 600 to 1200 milliseconds (mean, $820 \pm 35$ milliseconds).

In a limited number of experiments, the stimulating electrodes were moved $2 \mathrm{~mm}$ farther away from the recording electrode. The delay of EJPs prolonged and their amplitude decreased as the distance between both electrodes was increased. Fig. 7 shows records in an experiment in which the preparation was stimulated at about $3 \mathrm{~mm}$ and at about $5 \mathrm{~mm}$ from the recording electrode. The EJP after shifting the stimulating electrodes away delayed further about 10 milliseconds. The increased delay varied from preparation to preparation. Range of the increased dealys estimated from five experiments was from 5 to 20 milliseconds.

\section{3) Effects of drugs on the EJP}

a) Hexamethonium: The intramural nerve fibers stimulated might be pre- or post-ganglionic. This point was tested by adding the ganglion blocking agent, hexamethonium, to Krebs solution perfusing the strip. In the presence of hexamethonium $\left(10^{-4}\right)$, EJPs were not affected (Fig. 8),

a

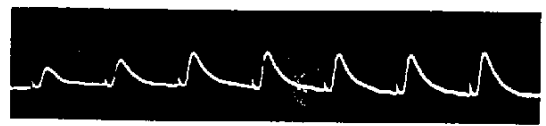

$\mathrm{b}$

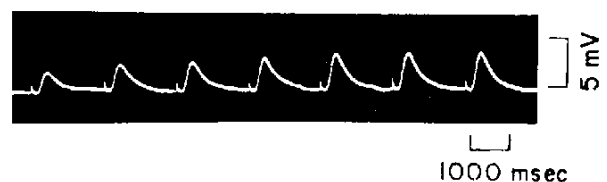

$a^{\prime}$
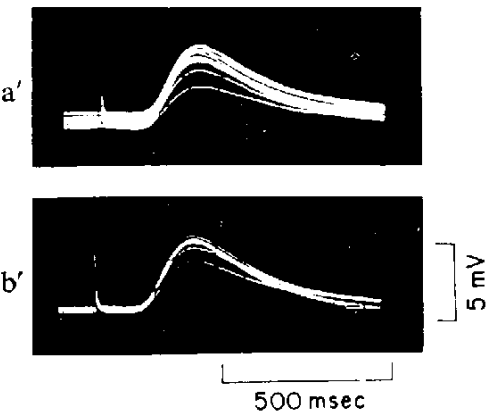

Fig. 8. Effect of hexamethonium on the EJP. (a), (a') Controls; (b), (b') in the presence of hexamethonium, $10^{-4}$. (a), (b) Records from a strip in Krebs solution containing $10 \mathrm{~m}$. magnesium ions; $\left(a^{\prime}\right)$, (b') superimposed records from another strip in Krebs solution containing $20 \mathrm{~mm}$ magnesium ions. Stimuli with square pulses of $0.1 \mathrm{msec}$ duration and $25 \mathrm{~V}$ at a frequency of $0.6 \mathrm{~Hz}$ wcre used throughout $(a)-\left(b^{\prime}\right)$.

a

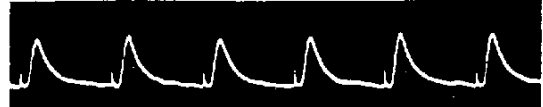

b

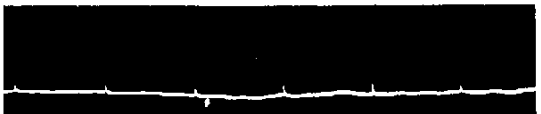

c

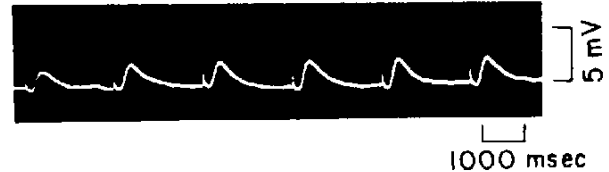

$a^{\prime}$

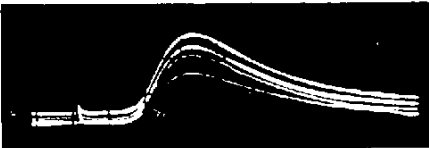

b
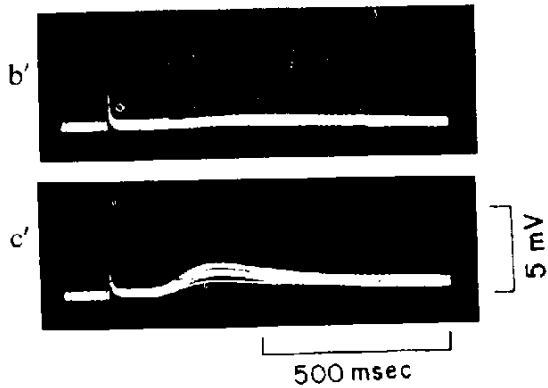

FIG. 9. Effect of atropine on the EJP.

(a), (a') Controls; (b), (b') 10 minutes after exposure to atropine, $10^{-\mathrm{B}} ;(\mathrm{c}),\left(\mathrm{c}^{\prime}\right)$ 25 minutes and 45 minutes after removal of atropine, respectively. (a)-(c) Records from a strip in Krebs solution containing $10 \mathrm{~mm}$ magnesium ions ; $\left(\mathbf{a}^{\prime}\right)-\left(\mathbf{b}^{\prime}\right)$ superimposed records from another strip in Krebs solution containing $20 \mathrm{~mm}$ magnesium ions. Stimuli with square pulses of $0.1 \mathrm{msec}$ duration and $25 \mathrm{~V}$ at a frequency of $0.6 \mathrm{~Hz}$ were used throughout (a)(c'). 
while they were completely abolished after application of tetrodotoxin. This result indicates that stimuli applied transmurally stimulate the postganglionic fibers. Occasionally duirng the exposure to hexamethoniun EJPs were enhanced slightly, sometimes leading to a spike.

b) Arropine and neostigminc: Fig. 9 shows the effect of atropine. In the presence of atropine at concentration of $10^{-8}$ or more, EJPs gradually decreased in amplitude and finally disappeared within several minutes. Usually, the EJPs failed to restore their initial amplitude after removal of atropine.

Neither hyperpolarizing response was evoked by transmuarl stimulation in normal preparations, nor the excitatory response was reversed to an inhibitory one after treatment with atropinc.

Neostigmine was used in concentrations of $10^{-8}, 2.5 \times 10^{-8}$ and $5 \times 10^{-5}$, When the strip was perfused with Krebs solution containing neostigmine, EJPs were always followed by spikes.

All these results and, in addition, the observation that acetylcholine depolarized the smooth muscle membrane (Fig. 10) while adrenaline or noradrenaline hyperpolarized it (Fig. 11), strongly suggest that the EJP is due to excitation of the post-ganglionic fibers, releasing a transmitter, probably acetylcholine which depolarizes the membrane, and that the oesophageal tissue appears to receive only the excitatory innervation.

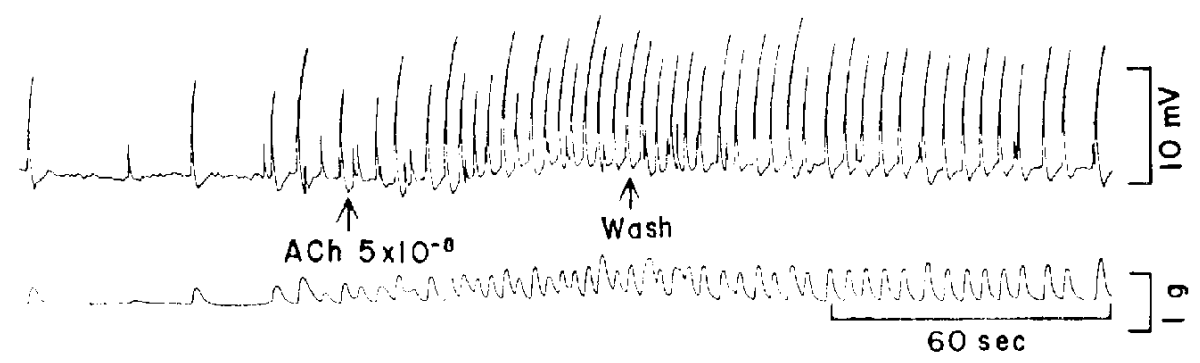

FIG. 10. Effect of acetylcholine on the membrane potential.

Acetylcholine, $5 \times 10^{-8}$, was applied at arrow $A C h$ and it was washed out at the time indicated by Wash. Note depolarization of the membrane.

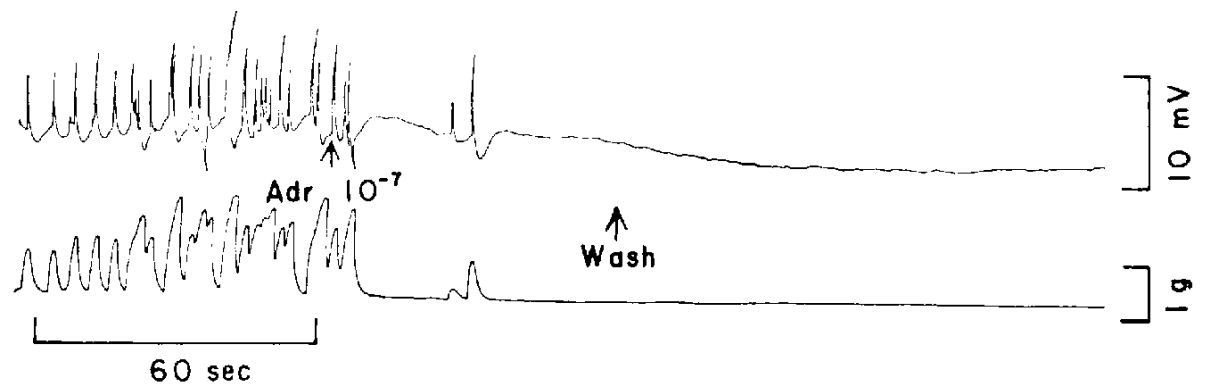

Fig. 11. Efrect of adrenaline on the membrane potential.

Adrenaline, $10^{-i}$, was applied at arrow Adr and it was washed out at the time indicated by Wash. The membrane was hyperpolarized and spontaneous activities were abolished. 


\section{DISCUSSION}

The smooth muscle cells of the oesophagus of the chicken showed spontaneous membrane activity. The action potentials spontaneously discharged, however, were variable in amplitude, shape and discharge interval. The main reason for this may be less synchronously firing of the individual cells. This interpretation is supported by the finding that application of acetylcholine or stimulation of the intramural nerves, by which a larger number of the smooth muscle cells would be fired synchronously, made the action potentials larger in amplitude and more regular in shape and discharge interval (see Fig. 2).

The oesophageal muscle sometimes showed dissociation between elcctrical and mechanical events, namely, spikes without developing tension. This dissociation occurred more frequently in strips from young chickens. A possible expalnation for this dissociation may be a failure of electrical activity in individual muscle cells to propagate through the smooth muscle cell population. Consequently, electrical activity in a limited number of cells no longer reflects the mechanical activity in this population: If tension in each cell contributes to the total tension, the fall in tension would be expected to be proportional to the decline in number of firing cells. An alternative explantation may be a rather weak mechanical interaction between the cells, so that the mechanical activity in this population would be not elicited until the electrical activity spreads to larger number of cells. It has been found that the muscular layer of the oesophagus in some species contains both striated and smooth muscle cells. If this was the case in the chicken oesophagus, the distribution of striated musele cells might be partly responsible for this dissociation. In fact, however, microscopic observations revealed no striated muscle cells in this part of the tissue (Sugimura, using an optical microscope, and Nonomura, using an electron microscope, personal communications). Apart from the validity of either explanation, the oesophageal smooth muscle of the chicken, especially of the young, appears to have a poorly developed functional continuity between neighbouring smooth muscle cells.

Transmural stimulation of the strip with short pulses gave depolarizing responses, i.e. excitatory junction potentials as reported in brief (8). Gillespie \& Mach (5) and Furness (3) have shown that stimulation of the intramural nerves of the colon of the rabbit gives rise to a transient depolarization of the smooth muscle membrane like the EJP. Bennett (1) has also shown that stimulation of the intramural nerves of the guinea-pig taenia coli gives rise to a depolarizing response. The rabbit colon and the guinea-pig taenia coli, however, receive dual innervation from the antagonistic nerve fibers and when stimulated transmurally the possibility would be not excluded that the depolarizing response may be affected to some extent by a hyperpolarizing response on simultaneous stimulation of the inhibitory nerves (25). In fact, Bennett (1) has found that smooth muscle cells of the guinca-pig teania coli generally give a hyperpolarizing response and only rarely give a depolarizing response and that a kind of interaction takes place between these opposing responses of individual cells.

The smooth muscle of the chicken oesophagus gave no hyperpolarizing response, nor were excitatory potentials reversed to inhibitory potentials in the presence of atropine. 
It can be therefore argued that there is little or no inhibitory innervation of the smooth muscle cells. In other words, this preparation has the great advantage that the process of impulse transmission from excitatory (cholinergic) nerve to smooth muscle may be investigated without taking into account the influence of inhibitory nerves.

The EJP was blocked by treatment with atropine and potentiated by neostigmine. Hexamethonium had no effect on the EJP. Acetylcholine therefore may be a mediator of the potentials, and be released from the postganglionic cholinergic nerves. This is in agreement with the finding that application of acetylcholine depolarized the membrane of the smooth muscle. The generally accepted view for the action of acctylcholine at the motor-end plate of skeletal muscle $(21,26-28)$ and on smooth muscle $(29,30)$ is a nonselective increase in permeability of the membrane to cations. The results obtained concerning the action of acetylcholine on the oesophageal smooth muscle of the chicken might be also explained by a similar hypothesis.

The EJPs have the same characteristics as those of the EJPs in the guinea-pig vas deferens and of the end-plate potentials in skeletal muscle treated with high magnesium solutions $(23,26)$. During repetitive stimulation, successive EJPs were facilitated and summation occurred at higher frequency. Depolarization, if large enough, triggered a spike. It appears from all these results that the cholinergic nerve-muscle junction operates in the essentially same manner as that of other neuromuscular junctions. The main difference is of the time course of EJPs. The latent period of EJPs in the oesophageal tissue was over 10 times larger than that of EJPs in the vas deferens $(24,31)$. A similar long latent period has been measured in junction potentials, regardless of whether inhibitory or excitatory, from the gastrointestinal smooth muscle $(1-3,32-34)$. This delay includes conduction lime of an impulse along the intramural post-ganglionic fibers from the stimulating site to the terminal and transmission time at the neuromuscular synapse. It appears, from the present experiments where EJPs were recorded at different distances from the stimulating electrodes, that the greater part of the latency is probably occupied by a synaptic delay. Conduction velocity of the intramural postganglionic fibers, however, can not be accurately measured, since the nerve fibers may not run straight, i.e. their length is unknown.

Recent microscopic studies have allowed observation of the fine structural relationship between autonomic nerve fibers and smooth muscle cells to be made and so far there are a number of descriptions of the neuromuscular junctions. In the rat or guinea-pig vas deferens, axons, many of them packed with synaptic vesicles, are most commonly found in the small irregular spaces between muscle eells, singly or in bundles, and more or less enclosed in Schwann ccll cytoplasma. Occasionally single axons are found to lie in close apposition $(200 \dot{A})$ to the muscle membrane. On the other hand, in the intestinal preparations such terminal axons are found in some of the larger intermuscular spaces and few or no axons are observed in close apposition with the muscle membrane. This shows that the muscular layer of intestines receives a sparse innervation. Yamauchi (35) and Suzuki, Nishiyama \& Inomata (36) suggested that the long latency of junction potentials in the 
intestinal smooth muscles could be explained by their sparse innervation and larger junctional space. Unfortunately, one has been unable to find any detailed information on the morphology of the innervation of the oesophagus of the chicken. If this relationship between structure and electro-physiological events could be generalized for neuromuscular junctions in smooth muscle tissues, the neuromuscular junction in the chicken oesophagus would be expected to have some similarities in structure to that of the intestinal smooth muscles.

\section{SUMMARY}

Spontaneous membrane activity of oesophageal smooth muscle of the chicken and transmission of excitation from the cholinergic nerve to the smooth muscle have been investigated with a sucrose-gap technique.

1. The resting membrane potential of the smooth muscle ranged from 39 to $53 \mathrm{mV}$ (mean, $49: 2.5 \mathrm{mV}, \mathrm{n}=14$ ). Some preparations showed spontaneous electrical and mechanical activities. The spontaneous spikes discharged with considerable variation in amplitude, shape and discharge interval. Each of such electrical discharges was usually followed by a rise in tension.

2. Stimulation of intramural nerves of the tissue gave an EJP with a spike potential, but never inhibitory potential. Tetrodotoxin completely abolished the response. In Krebs solution containing high magnesium ions, EJPs could be recorded without a spike.

3. Facilitation and summation of the EJPs were observed during successive stimuli.

4. The delay between nerve stimulation and onset of the EJP was from 90 to 160 milliseconds; the time to reach its maximum height was from 200 to 410 milliseconds; the time to decay to the half amplitude was from 130 to 300 milliseconds and it lasted from 600 to 1200 milliseconds.

5. Atropine abolished the EJP, but did not reversed it to an inhibitory potential. Neostigmine enhanced the potential and hexamethonium had no effect on it. Acetylcholine depolarized the membrane, while adrenaline or noradrenaline hyperpolarized the membrane.

6. These results suggest that the tissue receives only cholinergic excitatory innervation and therefore this offers a suitable preparation for investigating process of impulse transmission from autonomic cholinergic nerve to smooth muscle.

7. It scems that the cholinergic nerve-smooth muscle junction operates by the substantially same manner as that for the sympathetic nerve-smooth muscle junction of the guinea-pig vas deferens or other neuro-effector junctions.

Acknowledgcment: The author wishes to express his gratitude to Professor Akira Ohga for his encouragement during the course of this study and for his helpful criticism of the manuscript.

\section{REFERENCES}

1) Bennett, M.R.: J, Physiol. 185, 132 (1966)

2) Bennett, T.: J. Physiol. 204, 669 (1969) 
3) Furness, J.B.: J. Physiol. 205, 549 (1969)

4) Gillespie, J.S.: J. Physiol. 162, 76 (1962)

5) Gillespie, J.S. and Mach, A.J.: J. Physiol. 170, 19p (1964)

6) Bowman, W.C. and Everett, S.D.: J. Pharm. Pharmac. 16, Suppl. 72T (1964)

7) Taneike, T., OHashi, H. ANd OHGA, A.: Folia pharmac. jap. 64, $86 \$$ (1968)

8) OHashi, H. ANd Ohga, A.: Nature, Lond, 216, 291 (1967)

9) STÄmpFL, R.: Experientia 10, 508 (1954)

10) Burnstock, G. and Straub, R.W.: J. Physiol. 140, 156 (1958)

11) Bullbring, E. and Kuniyama, H.: J. Physiol. 169, 198 (1963)

12) Gillespie, J.S.: J. Physiol, 162, 54 (1962)

13) Kuriyama, H., Osa, T. and TOIDa, N.: J. Physiol. 191, 239 (1967)

14) Tomita, T.: J. Physiol. 183, 450 (1966)

15) Bülaring, E., Burnstock, G. and Holman, M.E.; J. Physiol. 142, 420 (1958)

16) Burnstock, G. and Prosser, C.L.: Am. J. Physiol. 199, 553 (1960)

17) Nagat, T. and Prosser, C.L.: Am. J. Physiol, 204, 910 (1963)

18) Prosser, C.L. and Sperelaxis, N.: Am. J. Physiol. 187, 536 (1956)

19) Nakamura, Y., Nakajima, S. and Grundffst, H.: J. gen. Physiol. 48, 985 (1965)

20) Narahashi, T., Moorf, J.W. and SCOtT, W.R.: J. gen. Physiol. 47, 965 (1964)

21) Kuriyama, H., Osa, T. and Toida, N.: Br. J. Pharmac, Chemother. 27, 366 (1966)

22) Nonomura, Y., Hotta, Y. and Onashi, H.: Science, N.Y. 152, 97 (1966)

23) Del Castillo, J. and Engiaek, L.: J. Physiol. 124, 370 (1954)

24) Kuriyama, H.: J. Physiol. 169, 213 (1963)

25) BENNETT, M.R.: Nature, Lond. 211, 1149 (1966)

26) Del Castillo, J. and Katz, B.: J. Physiol. 125, 546 (1954)

27) Dell Castillo, J. and Katz, B.: J. Physiol. 128, 157 (1955)

28) Takfuchi, A. and Takeuchi, N.: J. Physiol. 154, 52 (1960)

29) BC̈lbring, E. and Kurryama, H,: J. Physiol. 166, 59 (1963)

30) Burnstock, G.: J. Physiol. 143, 165 (1958)

31) Burnstock, G. and Holman, M.E.: I. Physiol. 155, 115 (1961)

32) Bennett, M.R., Burnstock, G. and Holman, M.E.: J. Physiol. 182, 541 (1966)

33) Büllbringi, E. ANd Tomita, T.: J. Physiol. 189, 299 (1967)

34) Burnstock, G., Campbell., G., Bennett, M.R. and Holman, M.E.: Nature, Lond. 200, 581 (1963)

35) Y Amauchi, A.: Acta Anat. Nippon 39, 22 (1964)

36) Suzuki, T., Nishiyama, A. and Inomata, H.: Symposium for Cell Chemistry 16, 29 (1966) 